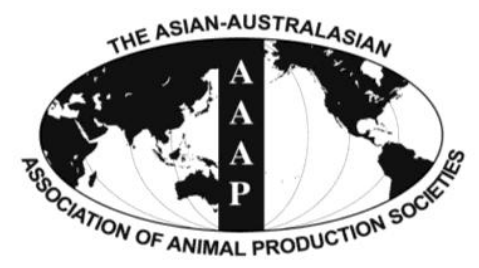

Asian-Aust. J. Anim. Sci.

Vol. 25, No. 9 : 1316 - 1321

September 2012

www.ajas.info

http://dx.doi.org/10.5713/ajas.2012.12083

\title{
The Regulation of Chemerin and CMKLR1 Genes Expression by TNF- $\alpha$, Adiponectin, and Chemerin Analog in Bovine Differentiated Adipocytes
}

\author{
Y. Suzuki, Y. H. Hong, S. H. Song ${ }^{1}$, A. Ardiyanti, D. Kato, K. H. So, K. Katoh and S. G. Roh* \\ Laboratory of Animal Physiology, Graduate School of Agricultural Science, Tohoku University, \\ Aoba-ku, Sendai 981-8555, Japan
}

\begin{abstract}
Adipokines, adipocyte-derived protein, have important roles in various kinds of physiology including energy homeostasis. Chemerin, one of adipocyte-derived adipokines, is highly expressed in differentiated adipocytes and is known to induce macrophage chemotaxis and glucose intolerance. The objective of the present study was to investigate the changes of chemerin and the chemokine-like-receptor 1 (CMKLR1) gene expression levels during differentiation of the bovine adipocyte and in differentiated adipocytes treated with tumor necrosis factor- $\alpha$ (TNF- $\alpha$ ), adiponectin, leptin, and chemerin (peptide analog). The expression levels of the chemerin gene increased at d 6 and 12 of the differentiation period accompanied by increased cytoplasm lipid droplets. From d 6 onward, peroxisome proliferator-activated receptor- $\gamma 2$ (PPAR- $\gamma 2$ ) gene expression levels were significantly higher than that of $d 0$ and 3. In contrast, CMKLR1 expression levels decreased at the end of the differentiation period. In fully differentiated adipocytes (i.e. at $d$ 12), the treatment of TNF- $\alpha$ and adiponectin upregulated both chemerin and CMKLR1 gene expression levels, although leptin did not show such effects. Moreover, chemerin analog treatment was shown to upregulate chemerin gene expression levels regardless of doses. These results suggest that the expression of chemerin in bovine adipocyte might be regulated by chemerin itself and other adipokines, which indicates its possible role in modulating the adipokine secretions in adipose tissues. (Key Words: Bovine, Adipocyte, Chemerin, CMKLR1, TNF- $\alpha$, Adiponectin)
\end{abstract}

\section{INTRODUCTION}

In ruminants, adipose tissues are the major lipogenic and lipid-storing organ that regulate energy homeostasis, meat quality and lactation (Laliotis et al., 2010). The discovery of leptin secretion by adipocytes provided another aspect of the adipose tissue not only as lipid storage, but also as an endocrine organ (Friedman and Ramirez, 1994). After leptin, there were other adipokines discovered that were secreted from the adipocyte, namely adiponectin, resistin and tumor necrosis factor- $\alpha$ (TNF- $\alpha$ ), etc. These adipokines are known to have various roles in physiological functions such as energy metabolism, inflammatory responses and in the vascular system. In addition to those

\footnotetext{
* Corresponding Author: Sang-gun Roh. Tel: $+81-22-717-8698$ Fax: +81-22-717-8701, E-mail: sanggun_roh@bios.tohoku.ac.jp 1 Laboratory of Animal Production, Faculty of Life and Environmental Science, Shimane University, Matsue, Shimane 690-8504, Japan.

Submitted Feb. 13, 2012; Accepted Mar. 23, 2012; Revised Jun. 24, 2012
}

adipokines, we previously identified another adipokine named chemerin, which is the ligand of orphan $\mathrm{G}$ proteincoupled receptor "CMKLR1 (chemokine-like-receptor 1)" with chemotactic properties (Wittamer et al., 2003; Roh et al., 2007). Recent studies suggest that chemerin may regulate insulin sensitivity and adipogenesis and have a potential role in the development of metabolic syndromes, such as obesity, diabetes and fatty liver disease (Kukla et al., 2010; Lehrke et al., 2009; Mussig et al., 2009). In addition, the detailed molecular mechanism of the regulation of chemerin expression has been reported (Bauer et al., 2011; Kralisch et al., 2009; Muruganandan et al., 2011). In our previous studies, chemerin was up-regulated during bovine adipocyte differentiation and chemerin analog regulated insulin secretion related to glucose metabolism and the release of triglycerides in sheep in vivo (Song et al., 2010; Suzuki et al., 2012). However, the factors regulating chemerin gene expression have not been well studied in bovine adipocytes. Therefore, this study was aimed to investigate the changes in chemerin and its receptor 
CMKLR1 gene expression during bovine adipocyte differentiation. We also addressed the regulatory effect of TNF- $\alpha$, adiponectin, leptin and chemerin analog instead of recombinant full-length chemerin on chemerin and CMKLR1 gene expression in bovine differentiated adipocytes.

\section{MATERIALS AND METHODS}

Isolation of bovine stromal-vascular (S-V) fraction cells including preadipocytes, and induction of adipocyte differentiation

The S-V fraction cells, which have an abundant population of preadipocytes, were isolated from the subcutaneous adipose tissues of male Japanese Black cattle and then differentiated to adipocytes as previously reported by Song et al. (2010) with a modification. Briefly, confluent $\mathrm{S}-\mathrm{V}$ fraction cells were incubated in DMEM/HAMF12 supplemented with $10 \%$ FBS, $1 \%$ antibiotic mix solution, octanoic acid $\left(5.0 \times 10^{-3} \mathrm{M}\right)$, sodium acetate $\left(10^{-2} \mathrm{M}\right)$, lipid mixture (100-fold dilution), $\mathrm{T}_{3} \quad\left(2.0 \times 10^{-9} \quad \mathrm{M}\right)$, dexamethasone $\left(10^{-8} \mathrm{M}\right)$, insulin $\left(10^{-7} \mathrm{M}\right)$ and troglitazone $\left(10^{-8} \mathrm{M}\right)$ for additional $12 \mathrm{~d}$. This differentiation medium was changed every $48 \mathrm{~h}$ during the adipocyte differentiation.

\section{Oil Red O staining}

Cultured adipocytes were stained with Oil Red $\mathrm{O}$ to observe the amount of lipid droplets in the cytoplasms. The procedure of Oil Red O staining was described previously (Song et al., 2010).

TNF- $\alpha$, adiponectin, leptin and chemerin analog treatment in differentiated adipocytes

After differentiation for $12 \mathrm{~d}$, adipocytes were incubated in DMEM/HAMF12 medium containing 10\% FBS and 1\% antibiotic mix solution for $24 \mathrm{~h}$ to remove the stimulus by differentiation-inducing reagents. The culture medium was then refreshed with DMEM/HAMF12 medium added to either with TNF- $\alpha(10 \mathrm{ng} / \mathrm{ml})$, adiponectin $(10 \mu \mathrm{g} / \mathrm{ml})$, leptin $(10 \mathrm{ng} / \mathrm{ml})$ or chemerin analog $\left(10^{-9}, 10^{-8}\right.$ or $\left.10^{-7} \mathrm{M}\right)$. After the adipokine treatments, the adipocytes were incubated for $24 \mathrm{~h}$ before proceeding to RNA extraction.
The chemerin analog $\left(\mathrm{NH}_{2}-\mathrm{yFLPsQFa}(\mathrm{Tic}) \mathrm{S}-\mathrm{COOH}\right)$ was prepared according to the previous report by Shimamura et al. (2009)

\section{Total RNA extraction and real time PCR}

Total RNA was extracted from cultured cells using RNAiso Plus (Takara Bio, Inc., Otsu, Japan). The quality and quantity of extracted total RNA were determined with a NanoDrop ND-1000 spectrophotometer (NanoDrop Technologies, DE, USA) and agarose gel electrophoresis. Total RNA (250 ng) was reverse-transcribed to cDNA using PrimeScript RT reagent (Takara Bio, Inc., Otsu, Japan). The sequence and amplicon sizes of the primers are shown in Table 1 with $18 \mathrm{~S}$ rRNA as the housekeeping gene. The reactions were performed in a $10 \mu \mathrm{l}$ of final volume containing $2 \times$ SYBR Premix Ex Taq II (Takara Bio, Inc., Otsu, Japan), $0.25 \mathrm{mM}$ of each primer, and $2 \mu \mathrm{l}$ from the RT product. Real-time PCR was carried out in DNA Engine Opticon 2 Continuous Fluorescence Detector (MJ Research, Ramsey, MN, USA) with initial denaturation at $95^{\circ} \mathrm{C}$ for 30 $\mathrm{s}$ and 45 cycles of denaturation at $95^{\circ} \mathrm{C}$ for $5 \mathrm{~s}$, annealing at $61^{\circ} \mathrm{C}$ for $20 \mathrm{~s}$, and extension at $72^{\circ} \mathrm{C}$ for $15 \mathrm{~s}$. Post-PCR melting curves were observed to confirm the specificity of single-target amplification, and the mRNA expression levels of the genes of interest were normalized with the housekeeping gene.

\section{Statistical analysis}

The data are expressed as the percentage of expression levels at $\mathrm{d} 0$ or that of control values (mean \pm SEM) and represent data collected form at least three experiments. The data from d 0 to 12 of bovine adipocyte differentiation were statistically analyzed using one-way analysis of variance (ANOVA) followed by Tukey's test. The data between control and adipokines treatment group were compared by Student's $t$-test. Differences in mean values between groups were considered to be significant at $\mathrm{p}<0.05$.

\section{RESULTS}

Gene expression levels of chemerin and CMKLR1 during bovine adipocyte differentiation

Oil Red O staining was performed to observe the lipid

Table 1. The sequences of primers used in this experiment

\begin{tabular}{|c|c|c|c|}
\hline$\overline{\text { Gene }}$ & Sequence $\left(5^{\prime}-3^{\prime}\right)$ & Product size (bp) & Accession no./reference \\
\hline \multirow[t]{2}{*}{$18 \mathrm{~S}$ rRNA } & Forward: GTAACCCGTTGAACCCCATT & 150 & (Ohtani et al., 2011) \\
\hline & Reverse: CCATCCAATCGGTAGTAGCG & & \\
\hline \multirow[t]{2}{*}{ Chemerin } & Forward: GTTTGTGAGGCTGGAGTTC & 173 & FJ594406.1 \\
\hline & Reverse: GAGTCTGTATGGGACAGTGC & & \\
\hline \multirow[t]{2}{*}{ CMKLR1 } & Forward: CATCGTCGTTCTGGAGGAGT & 168 & NM_001145235.1 \\
\hline & Reverse: GTTGAGGAACCAGACGGTGT & & \\
\hline \multirow[t]{2}{*}{ PPAR- $\gamma$} & Forward: CCAAATATCGGTGGGAGTCG & 101 & (Bionaz and Loor, 2008) \\
\hline & Reverse: ACAGCGAAGGGCTCACTCTC & & \\
\hline
\end{tabular}


(a) Oil Red O staining

Differentiation period (day)

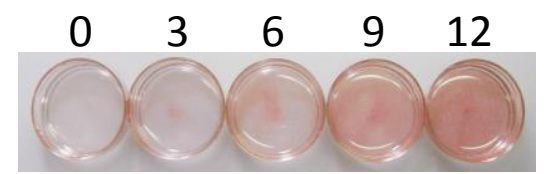

(b) Gene expression

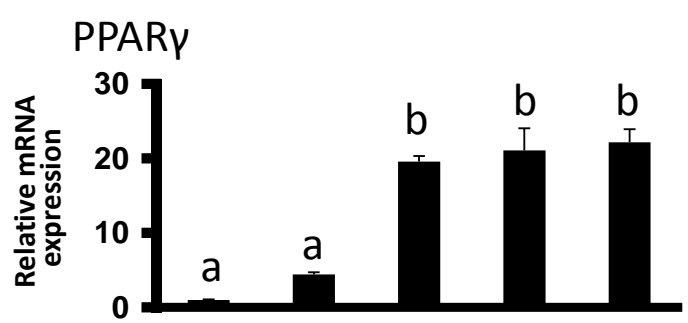

Chemerin

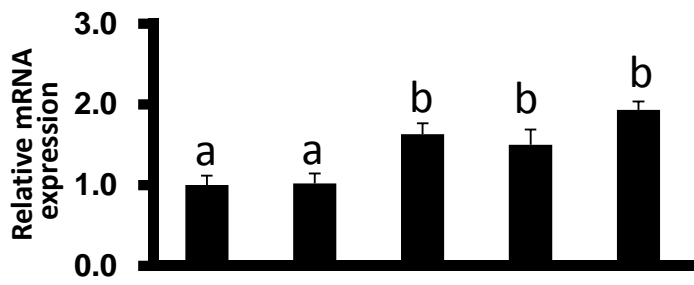

CMKLR1

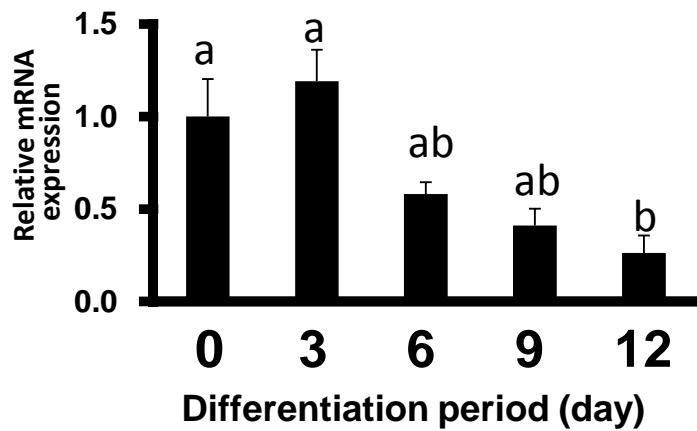

Figure 1. Lipid accumulation and gene expression levels of PPAR- $\gamma 2$, chemerin and CMKLR1 mRNA during bovine adipocyte differentiation. (a) Oil Red $\mathrm{O}$ staining of bovine differentiated adipocytes at indicated days of differentiation. (b) Gene expression level of PPAR- $\gamma 2$, chemerin and CMKLR1 when Oil Red $O$ staining was performed. The data for expression analysis are shown as means \pm SEM and collected from at least three experiments. The data were normalized with $18 \mathrm{~s}$ rRNA and expressed in relative to the expression levels of day $0 .{ }^{a, b}$ Values marked with different letters within each gene differ significantly $(\mathrm{p}<0.05)$

deposition in preadipocytes on $\mathrm{d} 0$ and differentiated adipocytes on d 3, 6, 9, and 12. As shown in Figure 1, the adipocyte differentiation was accompanied by an increased amount of lipid droplets. In Figure 1B, the level of gene expression of PPAR- $\gamma 2$ as differentiation-marker gene was upregulated almost 20 fold higher from d 6 to $\mathrm{d} 12$ than that at $\mathrm{d} 0$. On $\mathrm{d} 6$ and 12 , the gene expression levels of chemerin also increased significantly although with a slight fall at d 9. In contrast, CMKLR1 mRNA expression was decreasing on $\mathrm{d} 12$.

Effects of TNF- $\alpha$, adiponectin, and leptin on gene expression levels of chemerin and CMKLR1

We investigated the regulatory effect of $T N F-\alpha$, adiponectin, and leptin on chemerin and CMKLR1 mRNA expression in differentiated adipocytes. As shown in Figure $2 \mathrm{a}$ and $2 \mathrm{~b}, \mathrm{TNF}-\alpha$ and adiponectin treatments significantly elevated the gene expression levels of both chemerin and CMKLR1 in differentiated adipocytes. However, treatment of leptin did not seem to alter the gene expression levels of chemerin and CMKLR1 (Figure 2c).

Effect of chemerin analog on gene expression levels of chemerin and CMKLR1

To investigate the effect of chemerin analog on chemerin and CMKLR1 gene expression levels, differentiated bovine adipocytes were treated with chemerin analog at various doses. As shown in Figure 3, treatment of chemerin analog at $10^{-9}, 10^{-8}$ and $10^{-7} \mathrm{M}$ significantly upregulated the mRNA expression of chemerin but not its receptor. However, this stimulatory effect of chemerin analog in chemerin gene expressions was not shown in a dose-dependent manner.

\section{DISCUSSION}

In the present study, we have shown that the gene expression levels of chemerin and CMKLR1 in bovine adipocytes were altered during adipocyte differentiation and regulated by TNF- $\alpha$, adiponectin, and chemerin analog. Our results also demonstrated that the increasing level of chemerin gene expression was accompanied with the increased amount of lipid droplets and the increased expression of PPAR- $\gamma 2$. Adipocyte differentiation is known to be driven by adipogenic genes, e.g. PPAR- $\gamma 2$, CCAATT enhancer binding protein $(\mathrm{C} / \mathrm{EBP})$, and sterol regulatory element-binding protein 1 (SREBP1), which serve as transcriptional factors for their downstream genes involved in adipogenesis (Fajas et al., 1998; Lefterova and Lazar, 2009; White and Stephens, 2010). It has been reported that chemerin has PPAR- $\gamma$ response element (PPRE) in its promoter region and thus its gene expression is controlled by PPAR- $\gamma$ (Muruganandan et al., 2010). This report is in agreement with ours where there was a simultaneous increase of PPAR- $\gamma 2$ and chemerin during the adipocyte differentiation. In addition, SREBP2, a transcription factor that control sterol synthesis and is induced in adipocytes during obesity (Le Lay et al., 2004), binds to sterol 

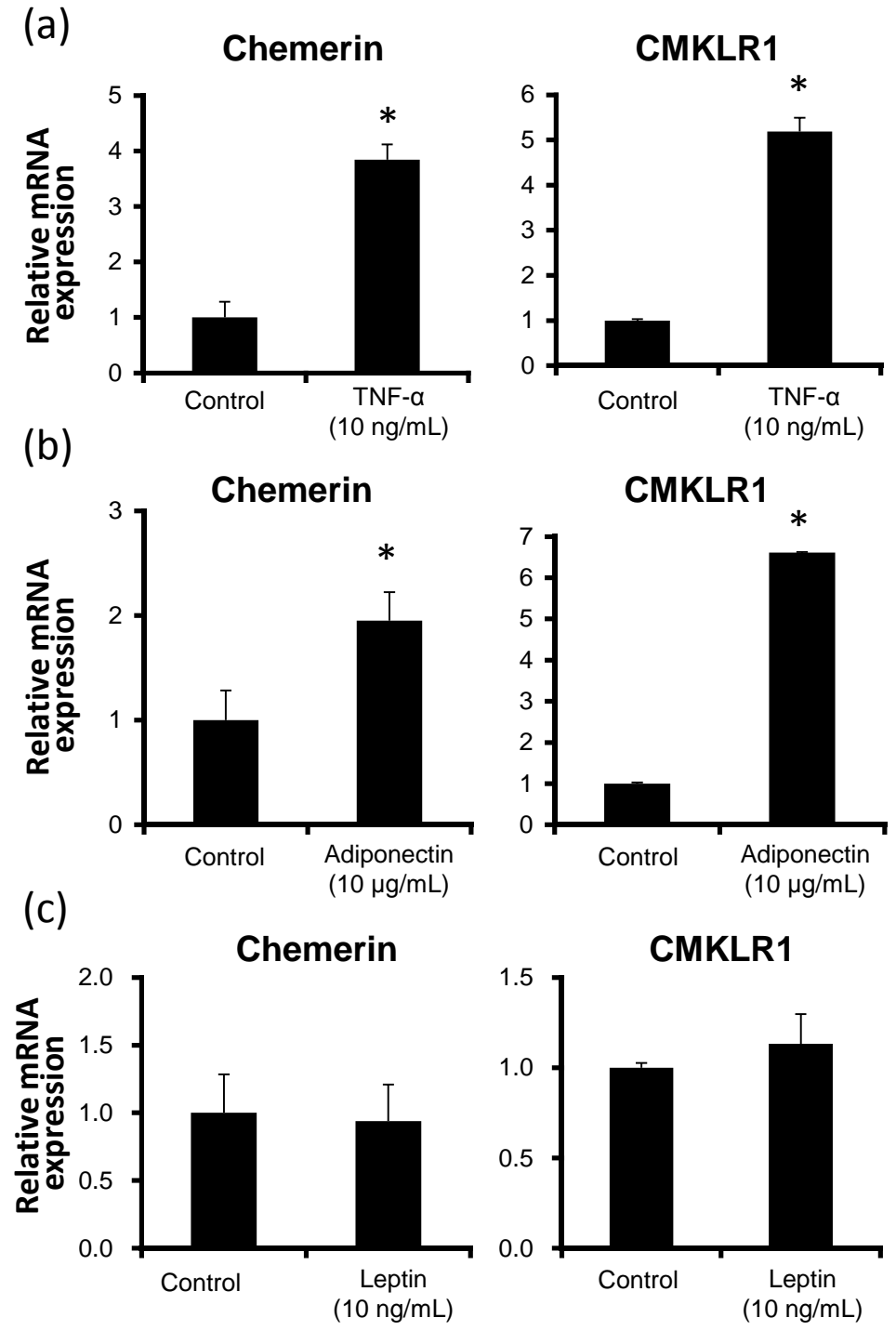

Figure 2. Gene expression levels of chemerin and CMKLR1 mRNA in bovine differentiated adipocytes treated with TNF- $\alpha$ (a), adiponectin (b) and leptin (c). The data are shown as means \pm SEM and represent data collected from at least three experiments. The data were normalized with $18 \mathrm{~s}$ rRNA and shown as means \pm SEM in relative to the levels of control cells ( $* \mathrm{p}<0.05 \mathrm{vs}$ control).

regulatory element (SRE) in the promoter of chemerin gene and upregulates its expression (Bauer et al., 2011). Thus, the stimulatory effect of adipocyte differentiation on chemerin gene expression can be explained by the increased PPAR- $\gamma 2$ gene expression levels and also probably by SREBP2 regulation.

As for CMKLR1, our results suggested that the expression level of CMKLR1 increased in the early stage of differentiation, but decreased later. Some studies have previously analyzed the expression of CMKLR1 during adipocyte differentiation and the results are divided into two opinions: one is the gradual upregulation of CMKLR1 gene expression levels during adipocyte differentiation (Goralski et al., 2007; Roh et al., 2007) and the other one is the downregulation of CMKLR1 gene expression at the end of differentiation, which is in agreement with our result
(Bozaoglu et al., 2007; Sell et al., 2009). Given the lowered gene expression level of CMKLR1 yet with the increase of chemerin expression levels as the differentiation progressed, we speculate that chemerin might direct its signal not to adipocyte as main target tissue, but rather stimulate macrophage infiltration causing inflammation in adipose tissue. This might explain for the possible chemerin role in altered metabolism of adipose tissue.

Large numbers of studies on TNF- $\alpha$ have indicated its physiological effects, which related to the induction of lipolysis, systemic inflammation in adipose tissue, and subsequently insulin resistance (Guilherme et al., 2008; Suganami and Ogawa, 2010). Also, adiponectin is currently considered to be a beneficial adipokine that ameliorates systemic inflammation in adipose tissues, improves insulin sensitivity and induces fatty acid oxidation (Combs et al., 


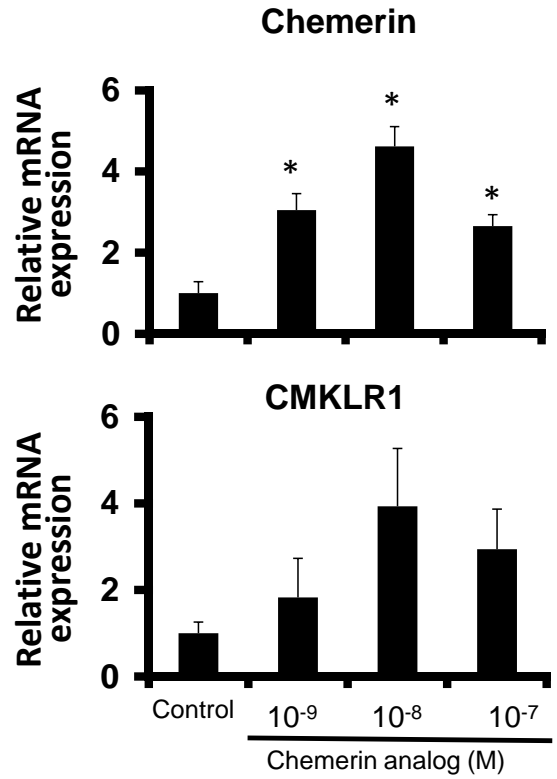

Figure 3. Gene expression levels of chemerin and CMKLR1 in bovine differentiated adipocytes treated with chemerin analog $\left(10^{-9}, 10^{-8}\right.$ and $\left.10^{-7} \mathrm{M}\right)$. The data are shown as means \pm SEM and represent data collected from at least three experiments. The data were normalized with $18 \mathrm{~s}$ rRNA and shown as means \pm SEM in relative to the levels of control cells $(* \mathrm{p}<0.05$ vs control).

2004; Yamauchi et al., 2002). In the present study, the treatments with TNF- $\alpha$ or adiponectin upregulated the gene expression levels of chemerin and CMKLR1 in differentiated adipocytes. This upregulation might result in a suppressive effect on fat accumulation in adipose tissue, suggesting that chemerin is one of the adipokines which is involved in changing the adipose tissue metabolic state into an anti-lipogenic process and inducing lipolysis.

In previous studies, the physiological effects of chemerin have been demonstrated to increase lipolysis and the downregulation of PPAR $\gamma$ gene expression (Roh et al., 2006), which also stimulates chemotaxis of macrophages and dendritic cells (Wittamer et al., 2003). Our results showed that the chemerin analog upregulated the gene expression of chemerin. This positive feedback pathway provides further information in the regulatory mechanism of chemerin expression as an adipokine modulating inflammation and metabolism of adipose tissue in differentiated adipocytes. However, the absence of change in CMKLR1 receptor gene expression level by the chemerin analog indicates that chemerin might not directly affect the gene expression of its receptor in bovine adipocytes.

In conclusion, the upregulation of chemerin and downregulation of CMKLR1 gene expression levels during adipocyte differentiation suggests their roles in the development and lipid metabolism of adipose tissue. Furthermore, the up-regulations of chemerin and CMKLR1 gene expression levels by TNF- $\alpha$ and adiponectin indicate the role of chemerin in inflammation and lipolysis in adipose tissues. Also, there is a positive feedback pathway in chemerin gene expression. These present results may offer new information to clarify the role of chemerin in modulating the adipogenesis and fat accumulation in ruminant adipocytes and adipose tissues.

\section{ACKNOWLEDGEMENTS}

This work was supported by the National Research Foundation of Korea Grant funded by the Korean Government (KRF-351-2009-1-F0016).

\section{REFERENCES}

Bauer, S., J. Wanninger, S. Schmidhofer, J. Weigert, M. Neumeier, C. Dorn, C. Hellerbrand, N. Zimara, A. Schaffler, C. Aslanidis, and C. Buechler. 2011. Sterol regulatory element-binding protein 2 (SREBP2) activation after excess triglyceride storage induces chemerin in hypertrophic adipocytes. Endocrinology 152:26-35.

Bionaz, M. and J. J. Loor. 2008. ACSL1, AGPAT6, FABP3, LPIN1, and SLC27A6 are the most abundant isoforms in bovine mammary tissue and their expression is affected by stage of lactation. J. Nutr. 138:1019-1024.

Bozaoglu, K., K. Bolton, J. McMillan, P. Zimmet, J. Jowett, G. Collier, K. Walder and D. Segal. 2007. Chemerin is a novel adipokine associated with obesity and metabolic syndrome. Endocrinology 148:4687-4694.

Combs, T. P., U. B. Pajvani, A. H. Berg, Y. Lin, L. A. Jelicks, M. Laplante, A. R. Nawrocki, M. W. Rajala, A. F. Parlow, L. Cheeseboro, Y. Y. Ding, R. G. Russell, D. Lindemann, A. Hartley, G. R. Baker, S. Obici, Y. Deshaies, M. Ludgate, L. Rossetti and P. E. Scherer. 2004. A transgenic mouse with a deletion in the collagenous domain of adiponectin displays elevated circulating adiponectin and improved insulin sensitivity. Endocrinology 145:367-383.

Fajas, L., J. C. Fruchart and J. Auwerx. 1998. Transcriptional control of adipogenesis. Curr. Opin. Cell Biol. 10:165-173.

Friedman, M. I. and I. Ramirez. 1994. Food intake in diabetic rats: relationship to metabolic effects of insulin treatment. Physiol. Behav. 56:373-378.

Goralski, K. B., T. C. McCarthy, E. A. Hanniman, B. A. Zabel, E. C. Butcher, S. D. Parlee, S. Muruganandan and C. J. Sinal. 2007. Chemerin, a novel adipokine that regulates adipogenesis and adipocyte metabolism. J. Biol. Chem. 282:28175-28188.

Guilherme, A., J. V. Virbasius, V. Puri and M. P. Czech. 2008. Adipocyte dysfunctions linking obesity to insulin resistance and type 2 diabetes. Nat. Rev. Mol. Cell Biol. 9:367-377.

Kralisch, S., S. Weise, G. Sommer, J. Lipfert, U. Lossner, M. Bluher, M. Stumvoll and M. Fasshauer. 2009. Interleukin1 beta induces the novel adipokine chemerin in adipocytes in vitro. Regul. Pept. 154:102-106.

Kukla, M., K. Zwirska-Korczala, M. Hartleb, M. Waluga, A. Chwist, M. Kajor, M. Ciupinska-Kajor, A. Berdowska, E. Wozniak-Grygiel and R. Buldak. 2010. Serum chemerin and vaspin in non-alcoholic fatty liver disease. Scand. J. Gastroenterol. 45:235-242. 
Laliotis, G. P., I. Bizelis and E. Rogdakis. 2010. Comparative approach of the de novo fatty acid synthesis (Lipogenesis) between ruminant and non ruminant mammalian species: From biochemical level to the main regulatory lipogenic genes. Curr. Genomics 11:168-183.

Le Lay, S., P. Ferre and I. Dugail. 2004. Adipocyte cholesterol balance in obesity. Biochem. Soc. Trans. 32:103-106.

Lefterova, M. I. and M. A. Lazar. 2009. New developments in adipogenesis. Trends Endocrinol. Metab. 20:107-114.

Lehrke, M., A. Becker, M. Greif, R. Stark, R. P. Laubender, F. von Ziegler, C. Lebherz, J. Tittus, M. Reiser, C. Becker, B. Goke, A. W. Leber, K. G. Parhofer and U. C. Broedl. 2009. Chemerin is associated with markers of inflammation and components of the metabolic syndrome but does not predict coronary atherosclerosis. Eur. J. Endocrinol. 161:339-344.

Muruganandan, S., S. D. Parlee, J. L. Rourke, M. C. Ernst, K. B. Goralski and C. J. Sinal. 2011. Chemerin, a novel peroxisome proliferator-activated receptor $\gamma(\operatorname{PPAR} \gamma)$ target ene that promotes mesenchymal stem cell adipogenesis. J. Biol. Chem. 286:23982-23995.

Muruganandan, S., A. A. Roman and C. J. Sinal. 2010. Role of chemerin/CMKLR1 signaling in adipogenesis and osteoblastogenesis of bone marrow stem cells. J. Bone Miner. Res. 25:222-234.

Mussig, K., H. Staiger, F. Machicao, C. Thamer, J. Machann, F. Schick, C. D. Claussen, N. Stefan, A. Fritsche and H. U. Haring. 2009. RARRES2, encoding the novel adipokine chemerin, is a genetic determinant of disproportionate regional body fat distribution: a comparative magnetic resonance imaging study. Metab. Clin. Exp. 58:519-524.

Ohtani, Y., T. Yonezawa, S. H. Song, T. Takahashi, A. Ardiyanti, K. Sato, A. Hagino, S. G. Roh and K. Katoh. 2011. Gene expression and hormonal regulation of adiponectin and its receptors in bovine mammary gland and mammary epithelial cells. Anim. Sci. J. 82:99-106

Roh, S. G., D. Hishikawa, Y.-H. Hong and S. Sasaki. 2006. Control of adipogenesis in ruminants. Anim. Sci. J. 77:472-477.
Roh, S. G., S. H. Song, K. C. Choi, K. Katoh, V. Wittamer, M. Parmentier and S. Sasaki. 2007. Chemerin-a new adipokine that modulates adipogenesis via its own receptor. Biochem. Biophys. Res. Commun. 362:1013-1018.

Sell, H., J. Laurencikiene, A. Taube, K. Eckardt, A. Cramer, A. Horrighs, P. Arner and J. Eckel. 2009. Chemerin is a novel adipocyte-derived factor inducing insulin resistance in primary human skeletal muscle cells. Diabetes 58:2731-2740.

Shimamura, K., M. Matsuda, Y. Miyamoto, R. Yoshimoto, T. Seo and S. Tokita. 2009. Identification of a stable chemerin analog with potent activity toward ChemR23. Peptides 30:1529-1538.

Song, S. H., K. Fukui, K. Nakajima, T. Kozakai, S. Sasaki, S. G. Roh and K. Katoh. 2010. Cloning, expression analysis, and regulatory mechanisms of bovine chemerin and chemerin receptor. Domest. Anim. Endocrinol. 39:97-105.

Suganami, T. and Y. Ogawa. 2010. Adipose tissue macrophages: their role in adipose tissue remodeling. J. Leukoc. Biol. 88:3339.

Suzuki, Y., S. H. Song, K. Sato, K. H. So, A. Ardiyanti, S. Kitayama, Y. H. Hong, S. D. Lee, K. C. Choi, A. Hagino, K. Katoh and S. G. Roh. 2012. Chemerin analog regulates energy metabolism in sheep. Anim. Sci. J. 83:263-267.

White, U. A. and J. M. Stephens. 2010. Transcriptional factors that promote formation of white adipose tissue. Mol. Cell. Endocrinol. 318:10-14.

Wittamer, V., J. D. Franssen, M. Vulcano, J. F. Mirjolet, E. Le Poul, I. Migeotte, S. Brezillon, R. Tyldesley, C. Blanpain, M. Detheux, A. Mantovani, S. Sozzani, G. Vassart, M. Parmentier and D. Communi. 2003. Specific recruitment of antigenpresenting cells by chemerin, a novel processed ligand from human inflammatory fluids. J. Exp. Med. 198:977-985.

Yamauchi, T., J. Kamon, Y. Minokoshi, Y. Ito, H. Waki, S. Uchida, S. Yamashita, M. Noda, S. Kita, K. Ueki, K. Eto, Y. Akanuma, P. Froguel, F. Foufelle, P. Ferre, D. Carling, S. Kimura, R. Nagai, B. B. Kahn and T. Kadowaki. 2002. Adiponectin stimulates glucose utilization and fatty-acid oxidation by activating AMP-activated protein kinase. Nat. Med. 8:12881295. 